\title{
SOME ANTIGENIC RELATIONS OF THE BIPOLARIS SEPTICUS GROUP OF BACTERIA*
}

LEE M. RODERICK

From the Veterinary Laboratory, North Dakota Agricultural Experiment Station

\section{INTRODUCTION}

Diseases of various animals, including the horse, ox, sheep, hog, fowl, and rabbit, have been described and the etiologic rôle in such conditions attributed to bacteria of the bipolaris septicus group. While these organisms are found under diverse conditions and in animals affected with what is commonly termed hemorrhagic septicemia, their pathogenicity is yet by no means clear, except perhaps in fowl cholera. The symptoms, and particularly the lesions of the disease, show a remarkable similarity in various hosts. The bacteria isolated therefrom agree in their morphologic features and cultural characteristics. The possibility exists that there is only a single organism, although there is little evidence to show that the various diseases are intertransmissible from one species of animal host to another, although the contagiousness of the conditions for some animals certainly is slight. The question arises, How pathogenic are these bacteria for their homologous hosts under natural conditions? That phase of the problem awaits further study lest too much be assumed without exact substantiation.

This study was undertaken for the purpose of making an immunologic comparison of various strains of the bipolaris organism by means of the complement-fixation reaction, and using the serum of hyperimmunized animals. If there is a true host specificity or a specific pathogenicity in animals, it might be ascertained from such studies. If there is an inherent difference in the bacterial protoplasm, it may be assumed that the antibodies resulting from the antigenic property of these bacteria may furnish means of differentiation. If several distinct organisms occur, it may be possible to demonstrate type or variety by means of the blood serum of animals naturally infected. This does not appear feasible since even routine immunologic methods appear impracticable in diagnosis of these conditions. Obviously the questions of unanimity of type or of numerous disease strains, as many as are

Received for publication, May 29, 1922.

* These studies were instigated while the writer was on leave of absence and permitted to work in the Pathological Division of the Bureau of Animal Industry, at Washington, during the winter of 1920. The experimental work was subsequently done at the North Dakota Agricultural College. 
susceptible hosts, have been debated, as will appear from a brief summary of available literature relative to both pathogenic and immunologic relationships of this group of bacteria.

\section{Historical}

Bollinger ${ }^{1}$ and others demonstrated the transmissibility and pathogenicity for rabbits, sheep and goats of material from animals which had died of wildund-rinderseuche. Pease ${ }^{2}$ observed an infection in Indian buffaloes which was transmissible not only to buffaloes but likewise to cattle, horses, pigs, guineapigs, rabbits, mice and pigeons. The bacteria were identified as those of rinderscuche. Holmes ${ }^{3}$ quotes Chamberland and Jouan as denying the specificity of Pasteurella for each species and contending that all forms of pasteurellosis are produced by the same microbe, more or less virulent and more or less adapted to different species of animals. Kitt ${ }^{4}$ states that fowl cholera was to be reproduced in none of the larger domesticated animals through feeding. Joest ${ }^{6}$ finds that the suisepticus is apparently as pathogenic for cattle, horses, sheep and goats as for hogs if injected intravenously.

Beck and Koske showed that a transmission of suisepticus through ingestion with the feed is possible in sparrows, crows, pigeons, chickens and geese. Ducks could not be infected. Koske states that the ease of transmission of the schweinepest to those types of birds through feeding is worthy of notice since feeding experiments with fowl cholera do not always lead to general infection. Furthermore, neither avisepticus nor suisepticus serum could be relied on to establish by the agglutination reaction a differentiation between suisepticus and avisepticus.

F. Hutyra ${ }^{7}$ asserts that with proportionate quantities of organisms almost any animal is to be infected by intravenous injection. He further reports that an immune serum produced with one variety furnishes active protection against the homologous strain, but the protective action fails or only partially succeeds against other varieties.

Hutyra and Marek ${ }^{8}$ report Wassermann and Ostertag as having observed that blood serum from animals which were highly immunized with cultures or extracts of Bacillus suisepticus protect usually only against the same strains of this bacillus, whereas it is without effect against other strains. On the other hand, Klepzow ${ }^{3}$ asserts that the blood serum of an animal strongly immunized against one member of the hemorrhagic septicemia group can be utilized as a curative agent against all forms of the disease.

Citron and Puitz ${ }^{10}$ likewise assert that there is a close relationship between the various strains. Mori ${ }^{11}$ found that an ovisepticus immune serum agglu-

1 Wild and Rinderseuche welche in Sommer 1878 in der Umgebung von München beobachtet wurde, 1878.

2 The Veterinarian, 1898,71 , p. 278.

3 Memoirs of the Dept. of Agriculture in India, 1914, 11, p. 105.

* Kitt, Th., in Geflügelcholera, Kolle und Wassermann: Handbuch d. Path. Mikroorg., 1913,6, p. 37

5 Schweinepest u. Schweineseuche, 1906.

* Arb. a. d. Kais. Gesundheitsamte, 1904-05, 22, ఐ. 503.

7 Septicemia Hemorrhagica, in Kolle und Wassermann: Handbuch. d. path. Microorg., 1913,6, p. 77 .

8 Special Pathology and Therapeutics of the Diseases of Domestic Animals, 1912, p. 137.

- Hygiene, 1903-04, 1, p. 221.

10 Ztschr. f. Hyg. u. Infektionskr., 1907, 56, p. 145.

11 Extract, Experiment Station Record, 1918, 38, p. 887. 
tinated the strains derived from other animals. Gallagher, ${ }^{12}$ in his work observed that an avisepticus strain which was virulent conferred a fair degree of immunity in rabbits against some strains of B. bovisepticus. Such rabbits resisted an infection with a virulent strain of $B$. suisepticus.

Authorities certainly differ regarding the question of whether there is but one or a multiplicity of strains. Clinical reports concerning the simultaneous occurrence of infections caused by these bacteria are rare. Such might naturally be expected if the extreme virulence which has been assigned to them is not substantiated.

The epidemiology and predisposing factors for these diseases are so obscure that explanations are indeed difficult. Fowl cholera and possibly infections in sheep are most common. Authorities who are not actuated by commercial reasons are agreed that infections in the larger domestic animals are not of common occurrence. Mohler and Eichhorn ${ }^{13}$ make the general statement that hogs became affected with swine plague following an outbreak of hemorrhagic septicemia in cattle. Further, the disease in sheep has developcd subsequently to an infection in hogs. However, in this connection an infection may possibly occur simultaneously in two or more animal species yet not involve the same particular strain of organism.

Matsuda ${ }^{14}$ studied by means of the complement-fixation test the relationship of the bipolaris bacteria to various immune serums prepared with different strains of the organism. He prepared vaccines by autolyzing the bacterial growth with distilled water and inactivating at $44 \mathrm{C}$. for 3 hours. It appears from the tables that a single injection brought about a reaction whereby the serum with an appropriate antigen readily bound the complement. The phenomenon was more marked if the injections were repeated. His data indicate that bovisepticus, suisepticus, and cuniculisepticus serums show a much higher degree of specific fixation with their homologous antigens than with heterologous bipolaris antigens. This apparently is a method whereby one might distinguish between the various strains of the group. Furthermore, it would appear that actual antigenic differences exist between the various animal strains which might or might not be represented by individual pathogenic characteristics.

\section{CULTIVATION AND GROWTH}

Cultures of those organisms included generally in the hemorrhagic septicemia group possess certain well defined characteristics. No others are considered in the studies included in this paper. A $3 \%$ glycerol agar with a reaction prior to sterilization of $P_{H} 7.2$ has given satisfactory results for cultivation. Such cultures are nonproteolytic in that they do not liquefy gelatin. No gas is formed from any carbohydrate although acid is produced from dextrose, sucrose, levulose, galactose and mannose. Iactose is not fermented, neither is any change produced in litmus milk. They are nonmotile, gram-negative and fail to grow on potato. The appearance of the growth in the broth of the fermentation tube shows the aerobic character of these

12 Jour. Am. Vet. Mer. Assn., 1917, 50, p. 708.

13 Am. Jour. Vet. Med., 1916, 8, p. 14.

14 Ztschr. f. Hyg. u. Infektionskr,, 1916, 66, p. 383. 
bacteria; the broth is perceptibly cloudy in the open arm, with growth slowly ascending in the closed arm with a clear line of demarcation marking the upper limit of growth. The bacteria are highly pathogenic for rabbits and may function as antigens in the complement-fixation test with a specific immune serum.

Besemer ${ }^{15}$ found the various strains to agree in their action on the various carbohydrates. He concludes that there seems to be no cultural or biochemical basis for designating by different names the five members of this group.

Bacteria which do not conform to these growth characteristics have been isolated from animals manifesting the symptoms and lesions designated as hemorrhagic septicemia. Such bacteria frequently have the characteristic bipolar staining property of the bipolaris group. Certain members of the paratyphoid, enteritidis group, B. coli, and B. proteus, may thus be easily mistaken for hemorrhagic septicemia bacteria. Some investigators assert that many organisms recently isolated from the animal body may show bipolar staining and yet possess few of the other cultural characteristics of the bipolaris group. Busson ${ }^{16}$ seems to include a great variety of bacteria as the causative agents of hemorrhagic septicemia. Their cultural reactions reveal little relationship however.

It is true that animal experimentation is a more definite method whereby the relative susceptibility of various animal species for these bacteria might be determined. If some strains have a well defined pathogenic effect on some species and not on others they might reasonably be expected to induce disease conditions in only their particular hosts. However, suisepticus and bovisepticus cultures are apparently incapable of regularly reproducing an infection in their respective hosts except such cultures be injected subcutaneously or intravenously. It is doubtful whether such bacteria are the primary cause of the infection or merely secondary invaders which take advantage of the lowered resistance on the part of the host. Perhaps in chickens the bipolaris organism plays a primary rôle, yet the widespread prevalence of fowl cholera in North Dakota during the winter and spring of 1921 associated with the isolation of farm flocks which there prevails, again compels one to consider the possibility. of predisposing influences even in infections with avisepticus in domestic fowls.

15 Jour. Bacteriot., 1917, 2, p. 177.

16 Centralbl. f. Bakteriol., I, 1921, 86, p. 101. 


\section{IMMUNOLOGIC METHODS}

Studies in the laboratories of the Pathological Division of the Bureau of Animal Industry of the Department of Agriculture have shown that commercial hyperimmune serums prepared for curative purposes against hemorrhagic septicemia will bind the complement in the presence of broth culture antigens of various members of the bipolaris group. The reaction is shown by all cultures which conform to the growth characteristics of this group. It matters not if the culture is a hemologous or a heterologous strain with which the serum was presumably prepared. If a culture of some other organism, e. g., paratyphoid, is used as a broth antigen with such a serum, no greater degree of specificity is shown by such a serum than the anticomplementary point as given by a normal horse serum. It must be said, however, that some commercial hemorrhagic septicemia serums show evidence that foreign bacteria have been used in their preparation. Obviously such serums would probably be unsatisfactory for identification of bipolaris cultures.

A commercial suisepticus serum (0.0055) was used for controlling the density and specificity of culture antigens. Little quantitative specificity was to be observed with this serum. As $0.05-0.1 \mathrm{c}$ c of serum is required to fix a quantity of broth antigen, it matters not whether a suisepticus or any heterologous strain is employed.

The question now arises, Were only cultures of one animal host variety employed in the preparation of this and similar serums which have given like results in the Bureau laboratories? Doubtless the manufacturers of such products employ cultures from many sources. Were all cultures for this serum derived from hogs? If they were, why do cultures from cattle, sheep, fowls, guinea-pigs and rabbits bind the complement and function as antigens in the same manner as suisepticus cultures? There are two probable explanations; one of them is that there is only a single organism - a view which is held by many. The other is that several varieties or types were used either knowingly or unintentionally in the preparation of commercial hyperimmune serums which are doubtless polyvalent.

As Matsuda worked with univalent serum, it was considered advisable to prepare serum from animals, using single cultures in order either to verify his findings or to confirm the general conclusions reached by the Bureau.

The experimental phases of this work deal, then, with the preparation of a number of specific immune serums from rabbits in which only 
a single culture strain was used on individual rabbits, and the testing for specificity of these serums against cultures isolated from various hosts by means of the complement-fixation test. It was suspected that such work might throw further light on the problem of whether one or many organisms infect different animals.

\section{SOURCE OF CULTURES}

It was necessary to work with cultures from well autherticated sources, otherwise misleading results might be obtained. Care was therefore exercised to secure cultures from laboratories in which they were originally isolated, or from investigators who could vouch for the species host of origin.

Cultures of the following strains were obtained from the Pathological Division of the Bureau of Animal Industry, United States Department of Agriculture: bovisepticus cultures K. C. 298 , Nos. 67 and 28 , suisepticus cultures No. 64, K. C. Nos. 8 and 9 ; ovisepticus cultures 56,52 and 47 , and avisepticus cultures No. 20 and Colorado 28 , cavia 65 and the rabbit strain,

The following were obtained from the Pathological Laboratory of the Colorado Agricultural

College: ovisepticus Colorado 33 , avisepticus Colorado 15 and suisepticus Colorado 13 .

The following were obtained from the Veterinary Department of the Kentucky Agricultural College: suisepticus cultures designated $\mathrm{Ky}_{2}, 2,3$ and 4 and avis spticus $\mathrm{Ky} .6$.

The following were isolated by the writer from the corresponding postmortem material: bovisepticus 6070 , avisepticus 58 and 59 and goose 6274 .

PREPARATION OF SPECIFIC SERUM

The process of preparation of the various serums from rabbits and the one horse so utilized was essentially the same throughout the work. Rabbits were bled priod to commencement of the immunization process. The normal serum so obtained was preserved for subsequent control. The normal serum in a quantity of $0.05 \mathrm{c}$ of no rabbit was found to produce appreciable fixation with the antigen subsequently used in its immunization. Vaccins were prepared from such cultures as were desired to be used in process of immunization. Care was exercised to use only one culture from a well authenticated animal origin on each group of rabbits throughout the process of immunization. Furthermore, necessary precautions were employed to insure freedom from contamination in such cultures. The cultures were grown for 24 hours on large agar slants containing 3\% glycerol. The growth was then removed and suspended in salt solution. No attempt was made to standardize such bacterial suspensions, but they were made preceptibly milky so that a rather heavy suspension was always employed. The suspensions were heated for 1 hour at $56 \mathrm{C}$.

The rabbits received from 4 to $6,2 \mathrm{cc}$ doses of the appropriate vaccine. There was little difficulty in producing a considerable degree 
of immunity in rabbits by such a process. That is, rabbits which received 5 subcutaneous injections at intervals of about 4 days of $2 \mathrm{cc}$ doses of a heavy, killed suspension of a hemorrhagic septicemia culture, later sustained without difficulty doses of living cultures which in like amounts killed untreated rabbits within 24 hours.

Live organisms were then employed to advance further the process of immunization. Small doses were given subcutaneously at first, then cautiously larger amounts were given and at times intravenous injections were attempted, but they frequently resulted disastrously, although large subcutaneous injections of live organisms were readily tolerated without fatal termination. As serum with a high antibody content was desired, care was exercised to prolong the process of immunization until preliminary tests with the blood showed perceptible amounts of complement-fixing antibodies for the homologous culture of bipolaris septicus. When it was found that the serum had attained considerable specificity for the antigen employed, the rabbits were bled and the serum preserved.

It hardly appears necessary to submit the schedules of immunization of all the rabbits employed in the preparation of serum. The character of the materials injected and the general scheme of injections were similar for the different series of rabbits. However, the following schedule is representative of the methods employed:

Rabbits 13, 15, 16:

Preparation of Serum with Ovisepticts 56

$7-1-202 \mathrm{c} c$ of the corresponding vaccin, subcutaneously.

7- 6.20 $2 \mathrm{c} \mathrm{c}$ of the corresponding vaccin, subcutaneously.

$7.12-202 \mathrm{c} c$ of the corresponding vaccin, subcutaneously.

7-14-20 $2 \mathrm{c} c$ of the corresponding vaccin, subcutaneously.

$7 \cdot 17-202 \mathrm{c} c$ of the corresponding vaccin, subcutaneously.

$7-22-20 \quad 1 \mathrm{c} c$ of a suspension of live organisms subcutaneously.

7-26-20 $1 \mathrm{cc}$ of a suspension of live organisms intravenously.

7.28.20 Rabbit 15 dead.

8- 7-20 No. $13,2 \mathrm{c} c$ of a suspension of live organisms subcutaneously.

8-12-20 No. 13,2 c $\mathrm{c}$ of a suspension of live organisms subcutaneously.

$8 \cdot 19-20$ No. $13,2 \mathrm{c} c$ of a suspension of live organisms subcutaneously.

8-23-20 No. 13, $1 \mathrm{c}$ c doses of live organisms subcutaneously.

8-30-20 No. 13, 1 c c doses of live organisms subcitaneously.

9- 4-20 No 13,1 cc doses of live organisms subcutaneously.

9. 7.20 No. $13,1 \mathrm{c} \mathrm{c}$ doses of live organisnis subcutaneously.

9.15-20 No. 13 bled for serum.

No especial attempt was made to determine the relative immunity of the rabbits at any stage of their immunization, although certain observations were possible. Neither was any attempt made to ascertain whether a specific immunity for only one strain had been developed; that is, are rabbits immunized to one strain likewise immune to strains of heterologous animal origin? One of the significant facts observed is the rate of development of immune bodies, or rather the rate at 
which complement-fixing antibodies are formed. I am not prepared to assert that such substances are identical or that the processes are parallel. This observation applies both to the rabbits and to the preparation of the immune serum from horse 6220. It was found on preliminary tests that even though an animal showed considerable immunity, no appreciable amounts of complement-fixing substances could be demonstrated. It was necessary to give further repeated injections, and, in order to obtain the maximum antigenic property, live organisms were employed before that animal's serum was suitable for the purposes of this experiment. The rate of development of a condition of immunity observed in rabbits substantiates the findings of Van Es and Martin ${ }^{17}$ and of Graham and Schwarze. ${ }^{18}$

Perhaps these observations have some practical applications and relationships. Since an animal responds so slowly to a stimulation with either an infection or to the process of immunization, as shown by the presence of immune bodies which can be demonstrated in vitro, there is small wonder that in an acute disease process induced by such organisms no substance of diagnostic value which can be demonstrated is as yet present. Likewise the question also arises, will small amounts of such vaccins as are commonly used induce sufficient immunity to protect an animal against field infection? It appears not, if appreciable amounts of virulent material are incorporated in the body of an animal with a high degree of susceptibility.

\section{QUANTITATIVE TITRATION OF SPECIFIC IMMUNE SERUMS}

It hardly appears necessary to outline all the routine steps in the performance of the complement-fixation reaction as applied to this work. Most of those details are in evidence from a study of table 1 . The same methods were used throughout the work.

The preparation and titration of the individual antigens were the essential steps in the work. Broth cultures of the various strains were employed as antigens, and usually glucose broth fermentation tubes which were inoculated and incubated from 24 to 48 hours were utilized. Only such fresh preparations are suitable. Such cultures are diluted with plain broth until the solution is opalescent rather than cloudy. Preliminary titration of such antigens with a known positive hemorrhagic septicemia serum $(0.0055)$ was always regularly performed. The antigenic point was thereby determined before it was

17 Nebraska Fxperiment Station Research Bulletins 17 and 18, 1920.

18 Jour. Am. Vet. Med. Assn., 1921, 59, p. 546. 
TABLE 1

Titration of Antiserums

\begin{tabular}{|c|c|c|c|c|c|c|c|c|c|}
\hline $\begin{array}{l}\text { No. of } \\
\text { Tube }\end{array}$ & $\begin{array}{c}\text { Ce of } \\
0.85 \% \\
\text { Salt } \\
\text { Solu- } \\
\text { tion }\end{array}$ & $\begin{array}{c}\text { C c of } \\
\text { Antigen }\end{array}$ & $\begin{array}{c}\text { Comple- } \\
\text { ment,* } \\
\text { Ce }\end{array}$ & $\begin{array}{l}\text { Serum } \\
0.0055 \\
\text { in } \mathrm{C} \mathrm{c}\end{array}$ & & $\begin{array}{l}\text { Ambo- } \\
\text { eeptor,f } \\
\text { C c }\end{array}$ & $\begin{array}{l}\text { Sheep } \\
\text { Cells, } \\
\text { 3\% Sus- } \\
\text { pension, } \\
\text { C c }\end{array}$ & & Results \\
\hline 1 & 1.5 & 0.05 & 1.0 & 0.2 & & 1 & 1 & & 0 \\
\hline 2 & 1.5 & 0.1 & 1.0 & 0.2 & & 1 & 1 & & + \\
\hline 3 & 1.5 & 0.2 & 1.0 & 0.2 & & 1 & 1 & & ++ \\
\hline 4 & 1.5 & 0.3 & 1.0 & 0.2 & & 1 & 1 & & $++t$ \\
\hline 5 & 1.5 & 0.4 & 1.0 & 0.2 & 0 & i & 1 & $\dot{0}$ & ++1 \\
\hline 6 & 1.5 & 0.5 & 1.0 & 0.2 & 5 & 1 & 1 & & +++ \\
\hline 7 & 1.5 & 0.6 & 1.0 & 0.2 & 6 & 1 & 1 & 5 & +++ \\
\hline 8 & 1.5 & 0.8 & 1.0 & 0.2 & $\underset{\varpi}{ }$ & 1 & 1 & 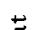 & +++ \\
\hline 9 & 1.5 & 1.0 & 1.0 & 0.2 & & I & 1 & $\pi$ & +++ \\
\hline 10 & 1.5 & 2.0 & 1.0 & $\begin{array}{c}0.2 \\
\text { Normal }\end{array}$ & 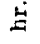 & 1 & 1 & $\dot{\Xi}$ & +++ \\
\hline & & & & horse & $\mathrm{T}$ & & & $\rightarrow$ & \\
\hline 1 & 1.5 & 0.05 & 1.0 & $\begin{array}{c}\text { serum } \\
0.2\end{array}$ & $\stackrel{5}{a}$ & 1 & 1 & s & 0 \\
\hline 2 & 1.5 & 0.1 & 1.0 & 0.2 & & 1 & 1 & & 0 \\
\hline 3 & 1.5 & 0.2 & 1.0 & 0.2 & 5 & 1 & 1 & 영 & 0 \\
\hline 4 & 1.5 & 0.3 & 1.0 & $0 . \overline{2}$ & $\stackrel{\Xi}{g}$ & 1. & 1 & \pm & 0 \\
\hline 5 & 1.5 & 0.4 & 1.0 & 0.2 & $\ddot{0}$ & 1 & 1 & ฮ్ & 0 \\
\hline 6 & 1.5 & 0.5 & 1.0 & 0.2 & $\Xi$ & 1 & 1 & $\vec{\Xi}$ & 0 \\
\hline $\bar{c}$ & 1.5 & 0.6 & 1.0 & 0.2 & g & 1 & 1 & 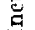 & 0 \\
\hline 8 & 1.5 & 0.8 & 1.0 & 0.2 & & $\overline{1}$ & 1 & & 0 \\
\hline 9 & 1.5 & 1.0 & 1.0 & 0.2 & & 1 & 1 & & 0 \\
\hline 10 & 1.5 & 2.0 & 1.0 & 0.2 & & 1 & 1 & & + \\
\hline
\end{tabular}

* Fresh guinea-pig serum so diluted that each ec contains $11 / 2$ units of complement as determined by previous titration.

+ Sheep-rabbit hemolytie amboceptor diluted so that each c e contains gi/2 units.

0 denotes complete hemolysis with no fxation of complement; +-+++ denotes varying degrees of deviation of complement.

TABLE 2

Table of Average Amounts of Serum Required for Fixation

\begin{tabular}{|c|c|c|c|c|c|}
\hline \multirow{2}{*}{ Rabbit Serum } & \multicolumn{5}{|c|}{ Culture Antigens } \\
\hline & Ovisepticus & Avisepticus & Suisepticus & Bovi & ictus \\
\hline \multirow{6}{*}{$\begin{array}{r}\text { Ovisepticus* } \\
\text { No. } 6645 \\
13 \\
32 \\
\text { Avisepticus } \\
\text { No. } 34 \\
6 \text { and } 8\end{array}$} & & & & & \\
\hline & $2 \mathrm{av} .0 .001 \mathrm{cc}$ & $2 \mathrm{av} \cdot 0.0015 \mathrm{ce}$ & $2 \mathrm{av}, 0.09 \mathrm{cc}$ & $1 \mathrm{req}$ & $10.1 \mathrm{ce}$ \\
\hline & 4 av. 0.0085 & 5 av. 0.01 & 5 av. 0.07 亿 & 3 ay. & 0.06 \\
\hline & 5 av. 0.011 & 5 av. 0.008 & 6 av. 0.025 & 3 av. & 0.64 \\
\hline & $\begin{array}{l}5 \text { av. } 0.013 \\
4 \text { av. } 0.005\end{array}$ & $\begin{array}{l}5 \text { av. } 0.013 \\
6 \text { av. } 0.005\end{array}$ & $\begin{array}{l}5 \text { av. } 0.044 \\
5 \text { av. } 0.044\end{array}$ & $\begin{array}{l}3 \text { av. } \\
3 \text { av. }\end{array}$ & $\begin{array}{l}0.04 \\
0.0665\end{array}$ \\
\hline & \multicolumn{2}{|c|}{43 titrations average $0.0087 \mathrm{ce}$} & \multicolumn{3}{|c|}{36 average $0.054 \mathrm{e} e$} \\
\hline \multirow{3}{*}{$\begin{array}{r}\text { Suisepticus } \\
\text { No. } 1 \\
28 \\
6220 \\
\text { Bovisepticus } \\
\text { No. } 1 \\
23\end{array}$} & $\begin{array}{l}4 \text { av. } 0.1 \text { e c } \\
4 \text { av. } 0.042 \\
3 \text { av. } 0.13\end{array}$ & $\begin{array}{l}5 \text { av. } 0.1 \\
5 \text { av. } 0.06 \\
3 \text { av. } 0.12\end{array}$ & $\begin{array}{l}6 \text { av. } 0.017 \\
5 \text { av. } 0.013 \\
4 \text { av. } 0.03\end{array}$ & $\begin{array}{l}3 \text { av. } \\
4 \text { av. } \\
2 \text { av. }\end{array}$ & $\begin{array}{l}0.009 \\
0.009 \\
0.05\end{array}$ \\
\hline & $\begin{array}{l}4 \text { av. } 0.08 \\
5 \text { av. } 0.06\end{array}$ & $\begin{array}{l}5 \mathrm{av}, 0.07 \\
5 \mathrm{av}, 0.1\end{array}$ & $\begin{array}{l}6 \text { av. } 0.014 \\
6 \text { av. } 0.028\end{array}$ & $\begin{array}{l}3 \mathrm{av} . \\
3 \mathrm{av} .\end{array}$ & $\begin{array}{l}0.02 \\
0.02\end{array}$ \\
\hline & \multicolumn{2}{|c|}{43 average $0.089 \mathrm{cc}$} & \multicolumn{3}{|c|}{42 average $0.018 \mathrm{c} \mathrm{c}$} \\
\hline
\end{tabular}

* Refers to type of culture used in immunization of rabbit. Number designates ribbit serum. 
possible to ascertain the relative potency of the specific rabbit serum against individual cultures.

It will be observed from table 1 , which is representative of all such preliminary titrations, that the titration is made with an increasing quantity of antigen against a constant quantity of suisepticus serum $(0.0055)$. It will be noted in this illustration that $0.3 \mathrm{cc}$ of antigen was sufficient to produce fixation. With a negative horse serum not even $1 \mathrm{cc}$ of the antigen was anticomplementary. Thus there is a high degree of specificity for the particular culture antigen titrated. When employed for quantitative titration against the rabbit serums 2 to 6 times (usually 3 times) the antigenic dose as shown by the preliminary titration was tested as a constant against decreasing dilutions of rabbit serums. Yet on the other hand, the test quantity of antigen should not approach the anticomplementary quantity.

\section{DISCUSSION}

The experimental work of this problem involved the testing of each serum against a number of homologous culture antigens and likewise against a variety of heterologous cultures. Serums were prepared from 2 cultures respectively of bovisepticus, suisepticus, ovisepticus, and avisepticus, and 1 of rabbit septicemia. Even casual examination of the records which necessarily are too cumbersome for publication shows that there is little to indicate that there are as many different strains as there are animal hosts. This differs markedly from the findings of Matsuda; on the other hand, it is quite evident that there was a wide difference in the amounts of a given serum necessary to produce fixation with the different culture antigens, other factors being uniform in each instance similar to the method followed in the Bureau laboratories.

A serum was obtained in the preliminary work from rabbit 6645 , immunized with ovisepticus 56 , which proved to be of comparatively high specificity and potency. This is particularly applicable when it is appreciated how difficult it is to induce the formation of immunity reaction producing substances with these organisms. Careful and repeated trials with different cultures and under a variety of conditions indicated that about $0.001 \mathrm{cc}$ of such serum was sufficient to produce complete fixation with ovisepticus and avisepticus cultures but that even $0.05 \mathrm{cc}$ gave little perceptible fixation with bovisepticus and stisepticus cultures. Such results being obtained, it was decided to prepare a series of serums as previously mentioned for further study and to determine whether similar specific relations would likewise exist. 
BIOMETRICAL ANALYSIS OF DATA

The data obtained can be better analyzed, not by a numerical tabulation of individual titrations, but rather by obtaining the average quantity of a serum which was just sufficient to produce fixation with the various culture antigens. This method of analysis has been selected since the results obtained are similar to those shown by the plotting of curves using the quantity of serum used in the tests as ordinates. The averages tabulated herewith agree with the peak of the superimposed curves secured by the graphic method of analysis. Serums prepared with cultures of sheep and fowl origin gave reactions which indicated no diference in antigenic character. Cultures of rabbit and of cavia origin gave results similar to those of fowl and sheep. Similarly, cultures of porcine and bovine origin are grouped together.

Analysis of the data shows that of the titrations the average amount of ovisepticus and avisepticus serum necessary to produce fixation with 36 titrations with ovisepticus and suisepticus cultures was 0.054 c $c$ but with 43 titrations with ovisepticus and avisepticus cultures it was but $0.0087 \mathrm{c}$.

Similarly with bovisepticus and suisepticus serums 43 titrations were made with ovisepticus and avisepticus cultures and 42 with the homologous group. Such serums required $0.018 \mathrm{c} \mathrm{c}$ to produce fixation with the homologous cultures, but with ovisepticus and avisepticus strains $0.083 \mathrm{c} \mathrm{c}$ was required.

As this problem originated in the Bureau laboratories, the Bureau requested permission to check the accuracy of the work done. Such serum as was available and cultures were furnished accordingly, and an analysis of the data so obtained reveals the fact that practically parallel results were there obtained. However, as a different proportion of titrations was made with some serums, using with some only a few cultures, than was here performed, the comparison is not exact. Further, the data of the Bureau includes figures with weak and comparatively impotent serums not employed by the writer. The work with ovisepticus and avisepticus serum show with 35 titrations with ovisepticus and avisepticus cultures $0.0197 \mathrm{cc}$ was sufficient to produce fixation, while with 35 with bovisepticus and suisepticus cultures $0.0475 \mathrm{cc}$ was required to produce fixation. Similarly with bovisepticus and suisepticus serums, 44 titrations with ovisepticus and avisepticus cultures $0.046 \mathrm{c}$ c was required to produce fixation, while with 38 titrations with bovisepticus and suisepticus serums only 0.0308 c c was necessary to produce fixation. 
It appears, therefore, that serum prepared with ovisepticus and avisepticus cultures will fix the competent in appreciably smaller quantities with avisepticus and ovisepticus than with either bovisepticus or suisepticus culture antigens. A similar relationship, although the specificity is not so great, exists between bosvisepticus and suisepticus serums and the homologous and heterologous serums. Potent serums show a much greater tendency to differentiate cultures in this manner than do weak serums, e. g., serum 6645.

There appears to be only 2 consistent exceptions to the foregoing groupings. Bovisepticus culture 6070 gave a much higher degree of specific fixation with ovisepticus and avisepticus serums than with bovisepticus or suisepticus serum. Likewise several titrations with avisepticus $\mathrm{Ky} .6$ appeared to group that organism with the bovineswine type rather than with the ovine-avian group. Those titrations are therefore omitted from a statistical study of the data of this laboratory.

A series of tests were also made using constant quantities of a given serum in tests against increasing quantities of broth antigens $(0.05-2 \mathrm{cc})$. The serum which was used in amounts of $0.02 \mathrm{cc}$ to eliminate better the group complement-fixing substances, was sufficient to bind the complement when only small quantities of culture antigens of the homologous group corresponding to the serum was used. When a heterologous culture was used specific fixation was absent. Those results further substantiate the previous data.

The serum of an animal immunized to either avisepticus or ovisepticus shows some ability to produce fixation with suisepticus or bovisepticus antigens, although it is less than for the homologous type antigen. This is explained on the basis of a group relationship and the formation of group complement-fixing substances. Specific complement-fixing substances are quite evidently present, so that it appears that there is not a single organism.

These antigenic relationships may be explained on the basis of two types of bacteria, a bovine-swine and an ovine-avian rabbit-cavia type. Whether these are 2 distinct organisms with reference to their pathogenic properties is an open question. This antigenic difference is apparently sufficient to justify the assumption that there is a difference in the specific protein composition of the 2 groups or types. That an infection may occur simultaneously in sheep and fowls, or be inter-transmissible, is not impossible. A difference in antigenic property was also noted between fowl-sheep cultures and hog-bovine strains 
masmuch as rabbits responded to immunization with avian and ovine strains and thereby developed more potent serums than the same corresponding treatment with swine and bovine strains. It was also noted that cultures isolated from fowls and sheep showed a considerably greater specificity when their antigenic titer was measured in titrating against serum 0.0055 than did hog-cattle strains in which the anticomplementary point was less far removed from the antigenic quantity. Those observations may be interpreted as meaning that the avian-ovine type is more pathogenic while the bovine-swine variety is more saprophytic. Routine diagnostic work has convinced me that fatal septicemic infections with this group of bacteria are so rare, except in fowls and occasionally in sheep, that type determination would be of no significance. It has been the purpose in this paper to show, however, that there is an appreciable antigenic specificity revealed by the reactions invoked in animals by these bacteria. Certainly a higher degree of immunity might be expected by immunization in fowls and sheep than in hogs and cattle from the same process. Furthermore, if control methods of these diseases involve immunization, it appears that a product prepared from one or more cultures of a given type would give satisfactory results on all homologots animal types.

\section{CONCLUSIONS}

Rabbits and a horse injected with bacterial material from bipolaris septicus cultures developed complement-fixing substances for the respective antigens. The rate of development of such substances was slow.

It appears from these studies that the reaction of animals to the process of immunization with these organisms is slow. This is revealed both by the rate of development of substances which can be demonstrated by the complement-fixation reaction and by the relative degree of resistance which is induced in the animals against a homologous infection. Such conclusions must necessarily reflect on the efficiency of current methods of immunization wherein an appreciable immunity is desired. These conclusions agree with those of investigators published elsewhere.

A series of complement-fixation tests between rabbit serums prepared by such methods and various cultures gave results which indicate that there are differences in the specific protein composition of such bacteria as revealed by their antigenic properties which may be explained by assuming that there are two types of the bipolaris septicus bacteria, a bovine-swine type and an ovine-avian-rabbit-cavia strain. 